\title{
Physical Capital, Human Capital, and Social Capital: The Changing Roles in China's Economic Growth
}

\author{
YUHENG LI, XUN WANG, HANS WESTLUND, AND YANSUI LIU
}

\begin{abstract}
This paper examines the roles of physical capital, human capital, and social capital in China's economic growth during the reform period 1981-2010. Empirical estimation confirms that physical capital and human capital contribute to the economic growth, probably due to the capital accumulation and the improvement of labor productivity. The impact of social capital turns from being insignificant in the 1980s and the 1990s to be positive in the 2000s, suggesting its rising importance in recent decades. A declining role of physical capital in the economic growth in China from 1990s to 2000s is also found. The findings hold for several additional robustness checks, including focusing on longer term determinants of the economic growth, subregional analysis, and endogeneity. Furthermore, the foreign direct investment inflows and adjustment of economic ownership structure are also important for economic growth in China.
\end{abstract}

\section{Introduction}

ince the reform process started in 1978, the Chinese economy has witnessed 9 percent average $\checkmark$ annual growth. Many empirical studies have explored the sources of the steady post-reform economic growth and analyzed influencing factors. First and foremost, physical capital investments have been found to play a key role for the Chinese economy since 1978 (Arayama and Miyoshi 2004; Chow 1993; Chow and Lin 2002; Ezaki and Lin 1999; Liu and Li 2006; Urel and Zebregs 2009; Yusuf 1994). Bai, Hsieh, and Yyingyi (2006) found that the annual return rate of physical capital investments was 20 percent in the post-reform Chinese economy. Li (1992), Li and Leung (1994), Liu and Li (2001), and Holz (2004) presented evidence that the post-reform Chinese economy has been positively affected by financial and monetary development (e.g., financial liberalization, banking reform, and liberalization) that may have further influenced the high rate of physical investment.

Human capital in terms of years of education has also been found to play an important role in the economic growth. It is believed that human capital contributes to technological improvement and innovation, which can help to advance the economy (Kuo and Yang 2008; Qian and Smyth 2005; Wang and Hu 1999; Wang and Yao 2003). Cai and Du (2000), Shen and Tian (2002), and Chen, Lu, and Yi (2004) found that 10-40 percent of the post-reform Chinese economic growth can be explained by the improvement of human capital. Further studies have also investigated the relationship between different educational levels and growth in China. Chi (2008) and Zhang and Zhuang (2010) concluded that tertiary education has had a positive and larger impact on gross domestic

Yuheng $\mathrm{Li}$ is a research associate in the Institute of Geographic Sciences and Natural Resources Research, Chinese Academy of Sciences, Beijing, China; His e-mail address is: liyuheng@igsnrrac.cn. Xun Wang is a research fellow in the China Economic Research Center, Stockholm School of Economics, Stockholm, Sweden. His e-mail address is: xun.wang@ hhs.se. Hans Westlund is a professor in the Architecture and Built Environment, Royal Institute of Technology (KTH), Stockholm, Sweden. His e-mail address is: hans.westlund@abe.kth.se. Yansui Liu is a professor in the College of Resources Science and Technology, Beijing Normal University, Beijing 100875, China. His e-mail address is: liuys@igsnrr.ac.cn. 
product (GDP) growth than primary and secondary education. Fleisher, Li, and Zhao (2010) indicated that workers with more than elementary school education have a much higher productivity than those with only elementary schooling.

Social capital in a number of studies at national and regional levels has been found to exert positive effects on economic growth (La Porta et al. 1997; Zak and Knack 2001), financial development (Guizo, Sapienza, and Luigi 2004), venture capital investment (Bottazzi, Da Rin, and Thomas 2007), trade (Guizo, Sapienza, and Luigi 2009), and entrepreneurship (Westlund and Bolton 2003). Particularly, with the decline of the relative importance of natural endowments for regional development and the convergence trend in human capital, social capital becomes increasingly important for economic growth (Mohan and Mohan 2002; Whiteley 2000). Basically, the core of social capital includes social networks and norms such as trust that have an impact on the potential for coordination and cooperation for mutual benefit. The main feature of current studies is that human activities always depend on social and cultural norms. Thus, not only the classical inputs but trustworthy relationships and a cooperative climate can generate positive externalities in the production process ( $\mathrm{Li}$ and Westlund 2013).

Theoretical arguments have also indicated that social capital reduces transaction costs, generates information spillovers, promotes the transmission of knowledge, and establishes cooperation (Westlund 2006). According to Arrow (1972:357), "virtually every commercial transaction has within itself an element of trust, certainly any transaction conducted over a period of time. It can be plausibly argued that much of the economic backwardness in the world can be explained by the lack of mutual confidence." In this sense, social capital, to a large extent, influences the roles of physical capital and human capital in economic growth. For instance, the perceived trustworthiness of a province may influence the location choice of foreign investment; communities with a good stock of social capital are more likely to benefit from higher educational achievement, better health in terms of life expectancy, and better economic performance. ${ }^{1}$

The study of social capital in China started only recently. Guanxi, or instrumental personal ties (Walder 1986), is considered to be important in Chinese society in terms of the resources within social networks that one can access and utilize. Since 1949, China's social capital has undergone enormous transformations. The period of strict central planning, collectivization, and people's communes formed controlled, centralized networks and norms with very limited opportunities for entrepreneurship and non-state controlled growth. After 1978, politically controlled networks are still important but the norms are different from the former period. Even more important is that the economy has opened up for private actors, with networks, norms, and values that did not exist in the former period. Thus, the social capital at various levels in China has changed. Improved communication technologies have brought economic activities into dense networks. More economic-driven factors have been added into the content of people's norms and values, which further influences decision making in terms of economic activities. Thus, the changing content of social capital generates impacts on the Chinese economy.

Studies of factors determining Chinese economic growth have mainly focused on physical capital and human capital. These studies have not included social capital as an important factor of the Chinese economy. How the changing social capital has influenced China's economic growth in the post-reform era still remains unclear. The research questions of this paper are has social capital generated any influence on economic growth in China? Are the economic roles of social, physical, and human capital changing over time? The paper aims to investigate these questions and provide some implications for policy making. 


\section{Human and Social Capital in Economic Growth}

Traditionally, variations in regional economic growth are explained by resource endowments such as the supply of natural resources and physical and financial capital. In the 1960s, scholars started to realize that labor was not a homogenous resource, but contained variations in human capital (Becker 1964; Schultz 1961). Ever since the 1990s, an increasing interest has been concentrated on the role of institutions and social capital, as factors of regional economic growth (Westlund 2007). It is widely accepted both theoretically and empirically that the accumulation of physical capital and human capital plays an important role in the economy. Therefore, this paper focuses on the relationship between social capital and economic growth.

The concept of social capital can be traced back to Hanifan (1916), who highlighted the importance of community participation in promoting schooling quality. Bourdieu (1986) pointed out two components of social capital: a resource that arises from membership in associations, communities, and social networks and a quality that arises from different interactions between actors. Coleman (1988) added a new dimension to the concept according to its function: a variety of entities acting to facilitate actors' actions in different organized structures. Social capital became an influential concept in the economic sphere after the publication of Making Democracy Work by Putnam, Leonardi, and Nanetti in 1993. They found that social capital matters in explaining regional differences in economic and institutional performance in the Italian regions. Following Putnam, social capital has two main aspects: structural social capital (networks and associations) and cognitive social capital (attitudes and norms of behavior, shared values, reciprocity, and trust). In general, there are many ways of defining the concept of social capital, but one broad expression that includes the contents of different definitions is social capital is broadly defined as the institutions, relationships, attitudes, and values that govern interactions among people and contribute to economic and social development (Grootaert and van Bastelaert 2002).

The connection between social capital and economic development has been highlighted in a large number of studies over the last 15 years (Westlund and Adam 2010). First, economic growth is considered as a type of social and cultural process and understanding of the formation and evolution of economic landscape needs the consideration of social institutions within which the economic activities take place (Martin 2000; Swank 1996; Thrift and Olds 1996). Places of better economic performance usually have dense social networks that integrate all kinds of institutions and organizations providing public goods and information. This implies that better economic performance contributes to the economic impact of social capital. Besides, a social environment where people meet and socialize is an ideal ground for the adoption and diffusion of norms and values that promote economic progress (Boulila, Bousrih, and Mohamed 2008).

In the economic field, it is increasingly accepted that social capital improves not only the capabilities of different agents at an individual level, but also their economic performance at an aggregate one. Becker (1974) considered social capital as an intermediate good for the productions of the basic needs of individuals. It is presented as an individual resource where rational and well-informed people invest in social capital within a utility maximization problem. In regions with high stocks of social capital, people are most likely to trust each other, engage in social networks, and participate in public affairs, which will help to reduce the transaction costs of economic activities (Fukuyama 1995). Tense social networks can contribute to generating information spillovers and promote transmission of knowledge. People within strong social networks would also take collective actions when facing internal or external challenges. Moreover, mutual trust helps to establish cooperation in $R \& D$ and information exchanges, which are important for innovation and industrial agglomeration (Pan and He 2010). 
In general, norms that can be considered as a social contract or unwritten rules, and trust that can be viewed as confidence in the reliability of others are highly related. Trustworthiness can be considered a civic norm that increases trust in others. The expectations that others will reciprocate are high in cases of high trust and people generally follow the prevailing civic norms in their behaviors (Knack and Keefer 1997). Societies characterized by high levels of trust are also less dependent on formal institutions to enforce agreements. Informal credit markets depending on strong interpersonal trust can facilitate investment where there is no well-developed formal system of financial intermediation or where lack of assets limits access to bank credit. The importance of social capital in enhancing trust is large in areas where law enforcement is deficient (Guizo, Sapienza, and Luigi 2004). Omori (2001) also points out that there is substitutability between social capital and institutions.

Many empirical studies have provided strong evidence that social capital plays an important role in influencing economic growth in the long run (Beugelsdijk and van Schaik 2001; Boulila, Bousrih, and Mohamed 2008; Helliwell and Putnam 1995; Knack and Keefer 1997). Over a more than three decade period since 1978, China has made great economic achievements. Although the investment of physical capital has mainly shaped the Chinese economy, there might be some connections between social capital and economic growth. Moreover, large economic disparities still exist among the eastern, central, and western provinces in China and the content of social capital and its economic role might also show large differences.

We formulate three research hypotheses: 1) social capital in China starts to generate economic impacts when the Chinese economy reached a certain stage before which the investment of physical capital was the major driving factor, 2) the economic role of physical capital declines with increasing economic development, 3) social capital in Eastern China, where the economy is well developed, would be the first to exert economic impact compared with the central and western regions.

\section{Data and Econometric Framework}

In this paper, our main focus is on the role of capital played in economic growth during the reform period. We classify capital into three different kinds (physical, human, and social) and examine their contributions on economic growth, respectively. The main method to analyze this consists of provincial panel data regressions with real per capital GDP growth as the dependent variable. Following the literature, after controlling for a series of explanatory variables identified in the literature, we specify our regression model as:

$$
G G D P_{i t}=\beta_{0}+\beta_{1} I N V_{i t}+\beta_{2} H U M A N_{i t}+\beta_{3} \operatorname{SOCIAL}_{i t}+\beta_{4} X_{i t}+\lambda_{t}+\xi_{i t}
$$

where $G G D P_{i t}$ is the measure of economic growth of province $i$ at year $t$, proxied by real per capita GDP growth. $I N V_{i t}$ is the investment ratio representing the physical capital; $H U M A N_{i t}$ is the measure of human capital of province $i$ at year $t$, proxied by student enrollment rate; SOCIAL $L_{i t}$ is the measure of social capital of province $i$ at year $t$, proxied by the number of social associations per 10,000 people; $X$ is a vector of control variables that influence the economic growth that includes economic openness (TRADE), measured by the ratio of export and import to GDP; foreign direct investment (FDI), measured by the ratio of utilized FDI to GDP; governmental expenditure (GOV), measured as the ratio of government budget expenditure to GDP; state ownership (SOE), measured by the share of state owned enterprises in total industry output value.

To capture the convergence effect, we introduce the lag term in logarithmic form of real per capital GDP, LNGNP ${ }_{i t-1}$. We also control fixed effects: $\alpha_{i}$ is the province-specific effect, $\lambda_{t}$ is the year 
effect. Finally, $\xi_{i t}$ is an unobserved error term that changes across time and among countries. Appendix 1 reports the definitions of variables and data source. We collect data for 29 provinces in China from 1981 to $2010 .^{2}$ Almost all the data are from National Bureau of Statistics. Appendix 2 reports the descriptive statistics for the main variables.

The paper uses the enrollment rate (ratio of the university and above students to the total population) as a proxy for human capital. The total population in each province includes people with the local household registration (hukou) and those without local hukou but who lived there for more than 6 months. However, the statistics of students in primary school, middle school, and high school usually refer to those who have the local hukou. The statistics of students in university and above include local students and those from other provinces. Thus, the calculation of human capital in the paper does not include students with local hukou. The ratio of university (and above) students to total population is more suitable as the proxy of human capital.

Measures of social capital in the literature include public participation, social connections, trust, and social norms (Knack and Keefer 1997; Putnam, Leonardi, and Raffaella 1993). La Porta et al. (1997) tested Putnam's hypothesis using data from the World Value Survey, where social capital is measured by the level of trust in each country. Trust ratios are computed as the percentage of individuals who think that "most people can be trusted." Guizo, Sapienza, and Luigi (2004) measured structural and cognitive social capital using electoral participation and blood donations. In China, social capital was first estimated by Zhang and Ke (2002), who measured it as the degree of trustworthiness of enterprises perceived by the business managers in a province. The level of provincial trustworthiness is assessed from managers' response to the question "According to your experience, could you list in order the top five provinces where the enterprises are most trustworthy?" The survey shows that the top five trustworthy provinces in China are Shanghai, Beijing, Jiangsu, Guangdong, and Shandong, while most western provinces are less trustworthy. However, the study only collected data in the year 2000 and did not examine its economic influence.

In this study, the measure of social capital covers the period 1990-2010 (Ministry of Civil Affairs of China 1991-2011). We measure social capital in terms of the number of associations for every 10,000 people to represent the structural capital of social networks and public participation. According to the China Civil Affairs Statistical Yearbook, an association is a reciprocal organization comprised by people sharing common characteristics and is non-profit and non-governmental in nature. The China Statistical Bureau started to collect official statistics of associations in each province since 1990. There is unfortunately no available data on trust or other forms of cognitive social capital at the provincial level in China. Therefore, this study is restricted to an examination of the role of structural social capital. The statistics show that the average (structural) social capital at the provincial level in China is 1.37 and the standard variation is 0.625 . The provinces with the highest and lowest levels of social capital are Zhejiang (2.33) and Henan (0.83). The statistics indicates that there is considerable variation of social capital among the provinces due to their economy and population.

\section{Empirical Analysis and Results}

The benchmark model. We first estimate the results of benchmark model using the full sample of panel data. The benchmark model contains the results of the impact of physical capital, human capital, and social capital separately (Columns 1-3, Table 1). The model also contains the results of the three "capitals" in three 10-year periods (Columns 4-6, Table 1).

Economic growth in China was under a convergence path during the research period. The full-sample regression shows that the estimated coefficients of INV and HUMAN are positive and 


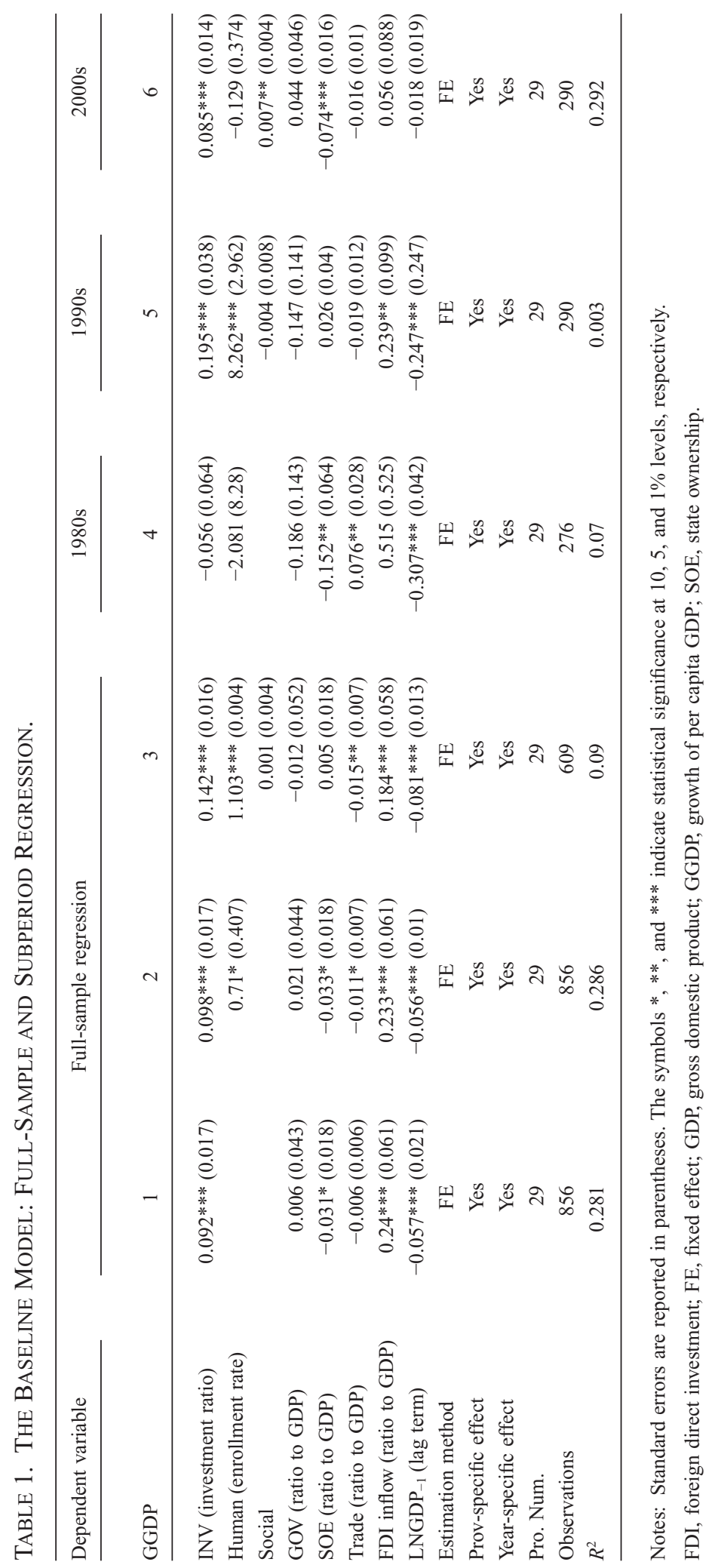


significant at the 1 and 10 percent levels. Keeping other things unchanged, a unit increase in physical capital and human capital will result in a 0.098 and 0.71 unit increase in the per capita GDP growth in China, respectively. This shows that on average, people's education played a crucial role in the Chinese economy in the research period. Social capital is insignificant in the regression results. However, the estimated coefficients of INV and HUMAN increased to 0.142 and 1.103 separately after the social capital was added into the regression. The significance of human capital also increased to the 1 percent level. The estimated coefficient of FDI inflow is positive at the 1 percent level. The reason is that FDI, which is highly associated with physical capital investment, is significant to the economic growth in China.

The role of the three capitals is examined in three 10-year periods separately as seen in Columns 4, 5, and 6. The estimated coefficient of INV is positive and significant at the 1 percent level in the 1990s and 2000s. However, there is a declining trend of the estimated coefficient of INV from 0.195 in the $1990 \mathrm{~s}$ to 0.085 in the $2000 \mathrm{~s}$. The estimated coefficient of HUMAN is significant and positive at the 1 percent level in the 1990s, but is not significant in the following years. Keeping other things unchanged, a unit increase in human capital results in a 8.262 unit increase in per capita GDP growth in China. The social capital is positive and significant at the 5 percent level in relation to per capita GDP growth in China in the recent decade. Keeping other things unchanged, a unit increase in social capital results in a 0.007 unit increase in per capita GDP growth in the 2000s. This indicates that people's social networks and their participation in public affairs started to generate positive economic impacts in China in the 2000s. Moreover, such a finding also corresponds to the research hypothesis that the significance of social capital emerges when economy develops to a certain stage.

The estimated coefficient of SOE is negative and significant at the 1 percent level in the 2000s. This shows that the SOE, which consists of major state-owned enterprises, has been restricting per capita GDP growth in China. Keeping other things unchanged, a unit increase in SOE will result in a 0.074 unit decrease in per capita GDP growth in China in the 2000s. This implies that the reduction of state-owned enterprises can contribute to economic growth in China.

Considering the possible transmission effect of the three capitals in their lag terms, we further analyze the benchmark model by introducing lagged terms of the three capitals in Table 2. In general, the results in Table 2 are in line with what is shown in Table 1. This indicates that physical, human, and social capital in their lagged terms exerted an influence on economic growth.

\section{Robustness Check}

Medium-term determinants. Chinn and Prasad (2003) and Chinn and Ito (2007) pointed out that one potential problem when analyzing developing countries is the possibility of measurement error in annual data. To avoid such a problem, we followed Chinn and Prasad (2003) and constructed a panel that contains non-overlapping 5-year averages of the data for each province. By taking such a measure, we are able to reduce short-term variations and identify the medium-term determinants of economic growth.

We perform the same modeling procedure as before, but estimate the model using 5-year average data. Columns 1, 2, and 3 in Table 3 present the results when we introduce the three capitals into the model, respectively. First, the convergence trend of the economic growth is found in the research period. Second, both physical capital and human capital are positively significant in the full-sample regression. Keeping other things unchanged, a unit increase in physical capital and human capital results in a 0.101 and 1.12 unit increase in per capita GDP growth in China, respectively. An increase 


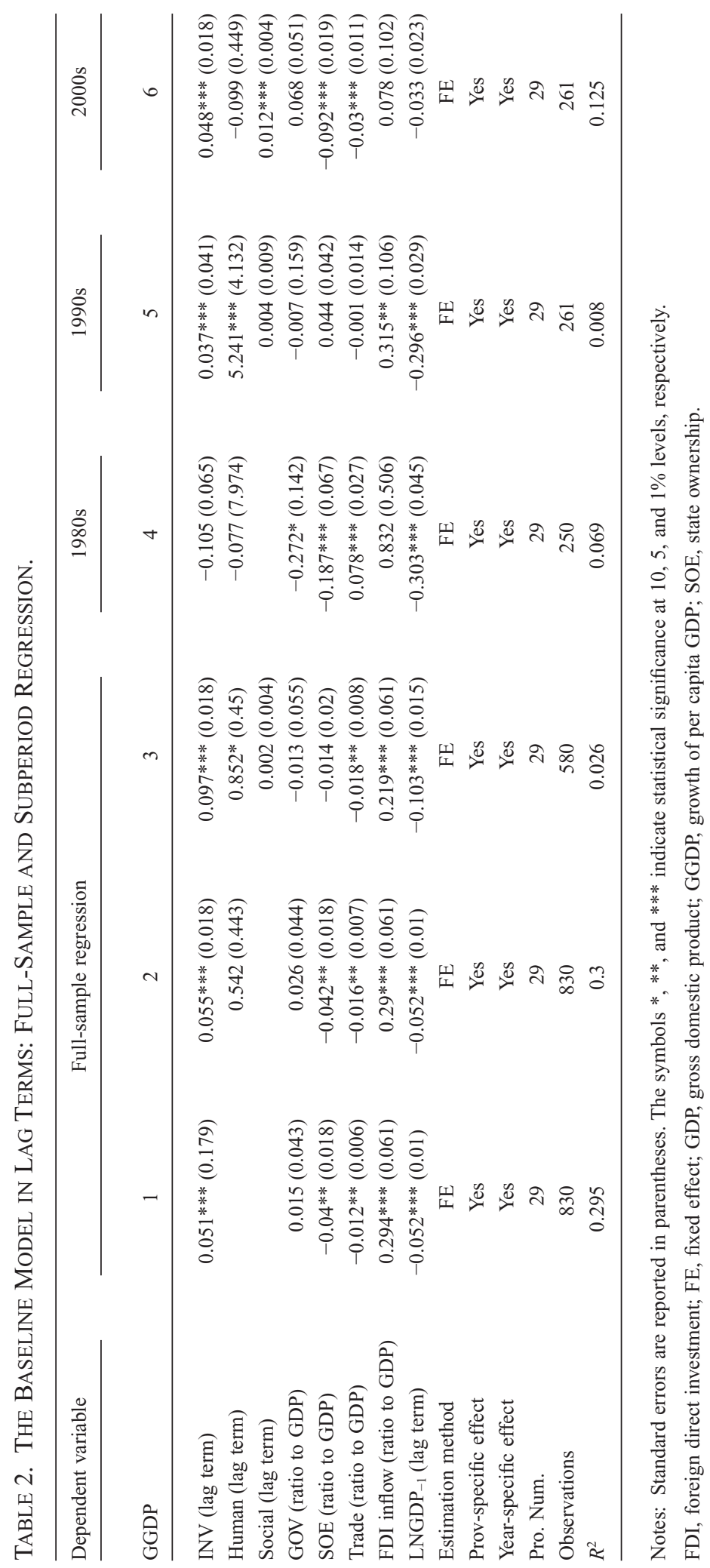


PHYSICAL CAPITAL, HUMAN CAPITAL, AND SOCIAL CAPITAL 141

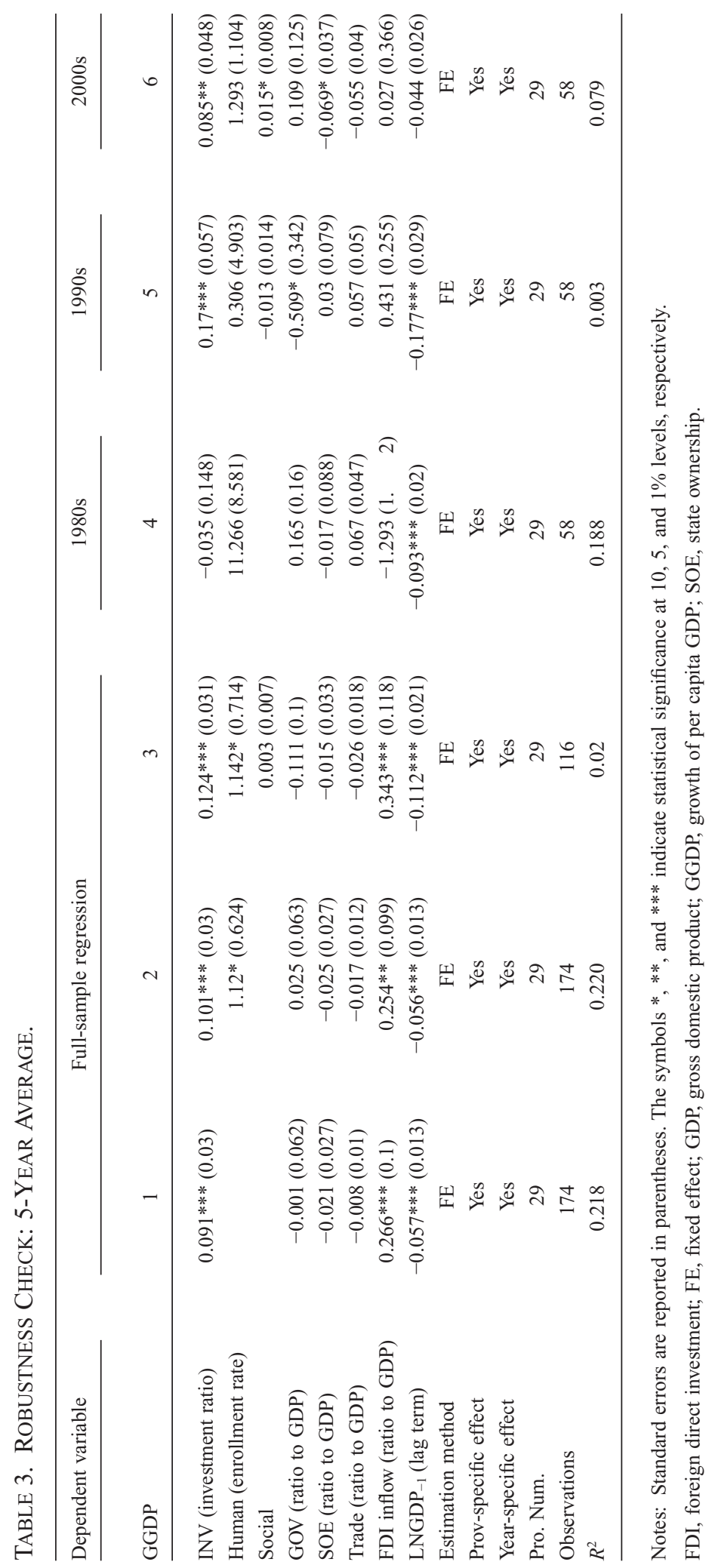


of the estimated coefficients of INV and HUMAN is also found after SOCIAL is included in the regression. Moreover, the estimated coefficient of FDI is positive and significant at the 1 percent level in the 30 -year period.

Columns 4, 5, and 6 in Table 3 present the results in three 10-year periods separately using the 5 -year average data. Besides the first 10 -year period, physical capital is positively and statistically significant in the other two 10-year periods. Keeping other things unchanged, a unit increase in physical capital results in a 0.17 and 0.085 unit increase in per capita GDP growth in China in the 1990s and 2000s, respectively. This indicates a declining role of investment of physical capital in recent decades, which is in line with the results in benchmark model. Human capital is significant (at the 5 percent level) in the 1990s and insignificant in the 2000s. Social capital starts to present positive significance at the 10 percent level in the period 2001-2010, which is in accordance with the result in Table 1.

Robustness check in different regions. We further made the robustness check in terms of the three super regions (eastern, central, and western) ${ }^{3}$ in China (Table 4). In the post-reform era, Eastern China has been leading the economic growth in China, and is ahead of the other two regions.

In general, economic growth converges in the three regions. The full-sample regression results show that the estimated coefficients of INV in the three regions are positively significant in the research period. Keeping other things unchanged, a unit increase in physical capital will result in $0.072,0.088$, and 0.121 unit increase in per capita GDP growth in the three regions, respectively. This implies that both the central and western provinces in China rely more on physical capital investment than do the eastern provinces. No significance is found for human capital in the eastern and central regions while the estimated coefficient of HUMAN is positive and significant at the 1 percent level in Western China.

The estimated coefficient of SOCIAL is positive and significant at the 5 percent level in Eastern China but social capital is not significant in Central and Western China. This finding is in line with the hypothesis that people's social networks and participation in public affairs have a positive economic impact in regions where the knowledge economy is more developed.

Robustness check: endogeneity. There is a possibility that the relationship between economic growth and capital accumulation might be driven by reverse causation. For instance, economic growth creates more physical resources for consumption as well as investment. Also, economic growth promotes the probability of industry updating and then creates demand for more educated labors. As another example, economic development raises the demand for mutual trust and social credit, which, in turn, favor the increase of social capital. These examples indicate that economic growth might demand the accumulation of social capital to improve the productivity and enhance the sustainability of the economy. To deal with this potential problem, we employ a generalized methods of moments panel estimator for dynamic models developed by Arellano and Bond (1991) and Arellano and Bover (1995). ${ }^{4}$ We estimate the model using both the difference and level terms. We use the lagged values in levels of all explanatory variables as instruments. Similarly, we use the lagged differences of all explanatory variables as instruments for the level variables. Table 5 exhibits the estimation results using dynamic panel.

Columns 1-3 present the results of full-sample regression employing "bottom-up" strategy. The estimated coefficients of INV and HUMAN are positive and significant at 1 percent level. Keeping other things unchanged, a unit increase in physical capital and human capital results in a 0.087 and 0.724 percent increase in per capita GDP growth in China, respectively.

Columns 4-6 list the estimation results of subperiod regression (1980s, 1990s, and 2010s), respectively. In the 1990 s and 2000s, physical capital is significant at the 1 percent level. However, 
PHYSICAL CAPITAL, HUMAN CAPITAL, AND SOCIAL CAPITAL 143

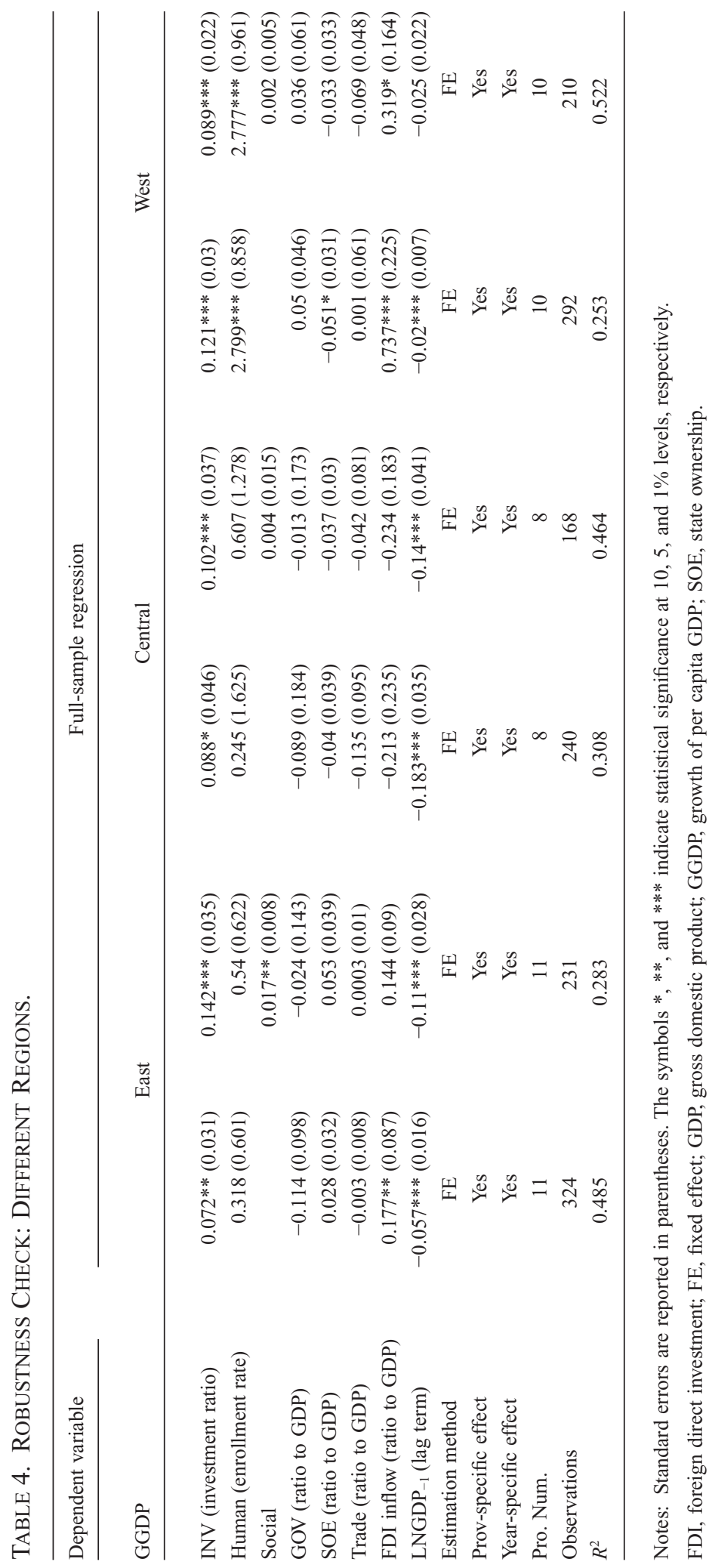




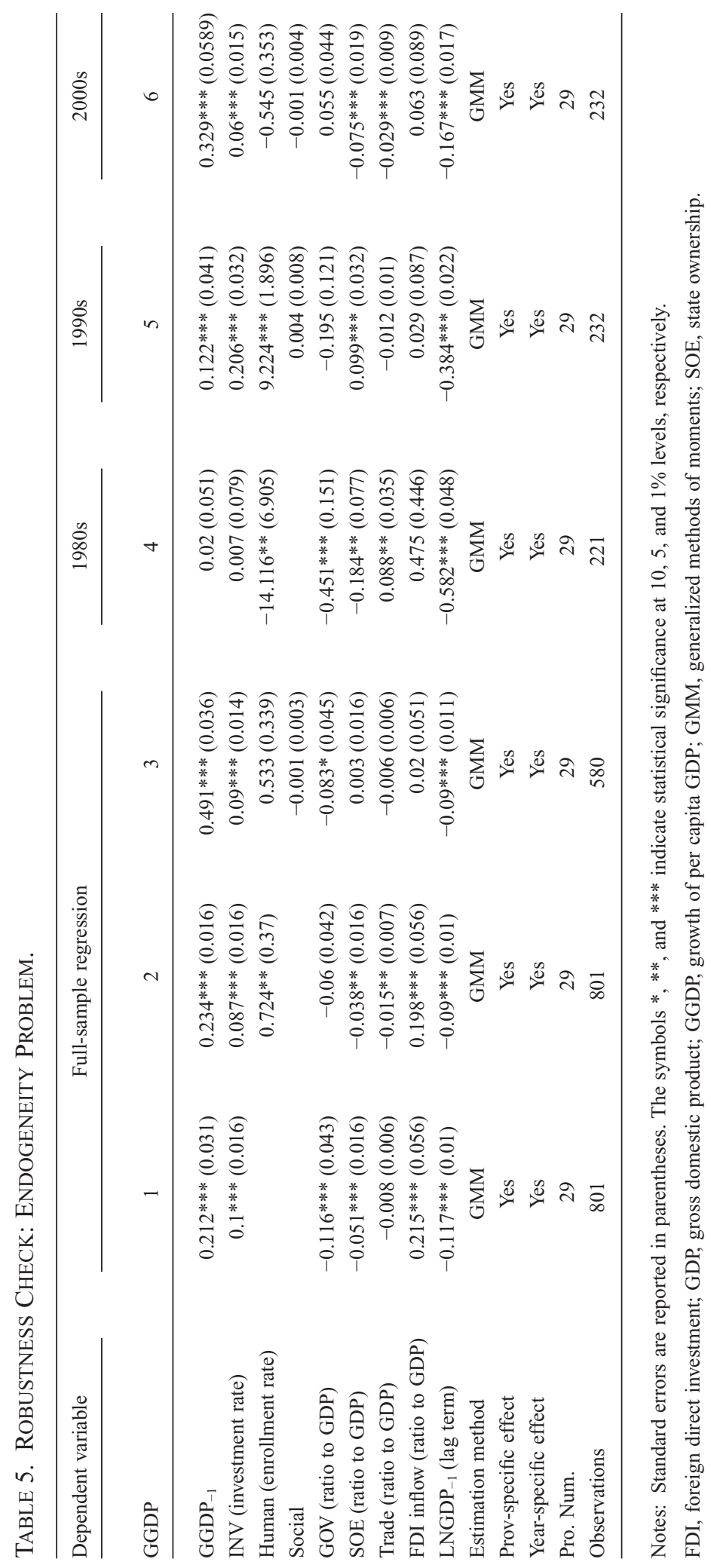


the estimated coefficient of INV decreased from 0.206 to 0.06 in the two 10-year periods, indicating its declining role in economic growth in China in recent decades. The estimated coefficient of HUMAN is positive and significant at the 5 percent level in the 1990s. However, no significance of human capital and social capital is found in the 2000s.

\section{Conclusion}

The paper investigated the changing roles of physical, human, and social capital in the Chinese economy in the post-reform period 1981-2010. Both the investment of physical capital and human capital were found to contribute to economic growth in China. For the first time, the research provides evidence of a positive correlation between social capital and Chinese economic growth in the 2000s, indicating the emerging economic role of social networks and people's participation in public affairs. The contribution of both human and social capital is also accompanied by the decline of the economic role of physical capital from the 1990s to the 2000s. Moreover, the economic impact of social capital is first indicated in Eastern China, which is more economically developed than the central and western provinces. Basically, the findings correspond well with the research hypotheses of the paper. On the one hand, social factors begin to generate their impact on the Chinese economy in the early twenty-first century. On the other hand, such an economic role emerges in places of a well-developed service-based economy. Thus, the positive connections between social capital and economic growth are strongly related in the Chinese context.

Social capital in China generated positive economic impact in the recent decade. Social associations, which are reciprocal organizations comprised of people with common characteristics, contribute to the reduction of transaction costs of economic activities and to information spillovers. Policy implications based on the research findings would be to support and encourage the creation of more bottom-up associations at various levels in China. Eastern China, which has seen the rising importance of social capital, should strengthen people's social networks, associations, and their participation in public affairs, which could help to increase their capacity to deal with economic risks and challenges. For the inland provinces with a comparatively lower economic level, it is also important to guide the development of social capital among individuals, enterprises, and communities before the economic role of physical capital starts to decrease in this region. Besides, in the countryside of China, the household registration system ${ }^{5}$ in which each household owns and manages a certain plot has weakened the individual households' capacity to resist natural and market risks ( $\mathrm{Li}$ 2013). Thus, rural organizations such as agricultural cooperatives and cooperative associations should also be encouraged and supported to unite peasants and enhance their capacity of mutual support in the rural economy.

It was not possible to include cognitive social capital (e.g., trust) into the study due to the lack of data. Because both structural social capital and cognitive social capital jointly influence people's decision making in economic activities, we believe that cognitive social capital is also an influential factor to the Chinese economy. However, people's trust in government and in others is weakened when government corruption is widely reported and when deceit and dishonesty occur. Thus, how cognitive social capital influences the economy at various levels in China is still a challenge for future research.

\section{Acknowledgement}

The written of the paper was supported by The Key Program of National Natural Science Foundation of China (41130748); National Natural Science Foundation of China (41301190); The Knowledge Innovation Program of the Chinese Academy of Sciences (KZCX2-EW-304). 
We thank Ding Sai Michael Funke, Marcel Timmer, Sandra Poncet, Kunyu Tao, Anders Johansson and other participants for their insightful comments at Conference on "Restructuring China's Economy", 16-17 August 2012, Stockholm, Sweden. [Correction added on 17 December 2014 after first online publication: Acknowledgement section was added in text.]

\section{NOTES}

1. Social capital is highly correlated with good educational outcomes, good health, and good government (Putnam 2000).

2. We do not include Chongqing and Tibet due to insufficient data availability. Taiwan, Hong Kong, and Macau are not included either.

3. Eastern China includes Beijing, Tianjin, Hebei, Liaoning, Shandong, Jiangsu, Shanghai, Zhejiang, Fujian, Guangdong, and Hainan; Central China includes Jilin, Heilongjiang, Shanxi, Henan, Anhui, Jiangxi, Hubei, and Hunan; Western China includes Neimenggu, Gansu, Ningxia, Qinghai, Shannxi, Sichuan, Chongqing, Guizhou, Yunnan, Guangxi, and Xinjiang

4. Besides endogeneity considerations, the dynamic panel approach can also control for the endogeneity of other explanatory variables.

5. In the early $1980 \mathrm{~s}$, the household responsibility system replaced the collective farming system in China, allocating certain land to each rural household who became responsible for both of its own profits and losses.

\section{REFERENCES}

Arayama, Y., and K. Miyoshi. 2004. Regional diversity and sources of economic growth in China. The World Economy 27(10): $1583-1607$.

Arellano, M., and S. Bond. 1991. Some tests of specification for panel data: Monte Carlo evidence and an application to employment equation. Review of Economic Studies 58(2): 277-297.

Arellano, M., and O. Bover. 1995. Another look at the instrumental variable estimation of error-components models. Journal of Econometrics 68(1): 29-51.

Arrow, K.J. 1972. Gifts and exchanges. Philosophy and Public Affairs 1(4): 343-362.

Bai, C.-E., C.-T. Hsieh, and Q. Yyingyi. 2006. The return to capital in China. Brookings Papers of Economic Activity 37(2): 61-102.

Becker, G. 1964. Human capital. Chicago, IL: University of Chicago Press.

1974. A theory of social interactions. Journal of Political Economy 82(6): 1063-1093.

Beugelsdijk, S., and T. van Schaik. 2001. Social capital and regional economic growth. Discussion Paper 2001-102, Tilburg University.

Bottazzi, L., M. Da Rin, and H. Thomas. 2007. The importance of trust for investment: Evidence from venture capital. Working Paper 325, IGIER (Innocenzo Gasparini Institute for Economic Research), Bocconi University.

Boulila, G., L. Bousrih, and T. Mohamed. 2008. Social capital and economic growth: Empirical investigations on the transmission channels. International Economic Journal 22(3): 399-417.

Bourdieu, P. 1986. The form of capital. In Handbook of theory and research for the sociology of education, ed. J. Richardson, 241-258. New York: Greenwood.

Cai, F., and Y. Du. 2000. The convergence and difference of the Chinese economic growth: Enlightenment to the West Development Strategy (in Chinese). Economic Research Journal 10: 30-37.

Chen, Z., M. Lu, and J. Yi. 2004. The regional difference of Chinese human capital and education development: Estimation of panel data (in Chinese). Journal of World Economy 12: 25-31.

Chi, W. 2008. The role of human capital in China's economic development: Review and new evidence. China Economic Review 19(3): 421-436.

Chinn, M.D., and H. Ito. 2007. Current account balances, financial development and institutions: Assaying the world "saving glut." Journal of International Money and Finance 26(4): 546-569.

Chinn, M.D., and E. Prasad. 2003. Medium-term determinants of current accounts in industrial and developing countries: An empirical exploration. Journal of International Economics 59(1): 47-76.

Chow, G. 1993. Capital formation and economic growth in China. Quarterly Journal of Economics 108(3): 809-842.

Chow, G.C., and A.-I. Lin. 2002. Accounting for economic growth in Taiwan and mainland China: A comparative analysis. Journal of Comparative Economics 30(3): 507-530.

Coleman, J. 1988. Social capital in the creation of human capital. American Journal of Sociology 94: 95-120. 
Ezaki, M., and S. Lin. 1999. Growth accounting of the Chinese economy: 1981-1995. Asian Economic Journal 13(1): 39-71.

Fleisher, B., H.Z. Li, and M.Q. Zhao. 2010. Human capital, economic growth and regional inequality in China. Journal of Development Economics 92(2): 215-231.

Fukuyama, F. 1995. Trust: The social virtues and the creation of prosperity. New York: Free Press.

Grootaert, C., and T. van Bastelaert. 2002. Understanding and measuring social capital, a multidisciplinary tool for practitioners. Washington, DC: World Bank.

Guizo, L., P. Sapienza, and Z. Luigi. 2004. The role of social capital in financial development. American Economic Review 94(3): 526-556.

- 2009. Cultural biases in economic exchange. Quarterly Journal of Economics 124(3): 1095-1131.

Hanifan, L. 1916. The rural school community center. Annals of the American Academy of Political and Social Sciences 67: 130-138.

Helliwell, J., and R. Putnam. 1995. Social capital and economic growth in Italy. Eastern Economic Journal 21(3): $295-307$.

Holz, C. 2004. Deconstructing China's GDP statistics. China Economic Review 15(2): 164-202.

Knack, S., and P. Keefer. 1997. Does social capital have an economic payoff? A cross-country investigation. Quarterly Journal of Economics 112(4): 1251-1288.

Kuo, C.-C., and C.-H. Yang. 2008. Knowledge capital and spillover on regional economic growth: Evidence from China. China Economic Review 19(4): 594-604.

La Porta, R., F. Lopez-de-Silanes, A. Shleifer, and V. Robert. 1997. Trust in large organization. American Economic Review 87(2): 333-338.

Li, K.W. 1992. Savings, foreign resources and monetary aggregates in China 1954-1989. China Economic Review 3(2): $125-134$.

Li, K.W., and W. Leung. 1994. Causal relationships among economic aggregates in China. Applied Economics 26(12): 1189-1196.

Li, Y.H. 2013. Agricultural cooperatives for urban-rural interaction in China. Italian Journal of Regional Science 12(1): 75-84.

Li, Y.H., and H. Westlund. 2013. Social capital and economic growth in China: Panel data analysis. In Social capital and rural development in the knowledge society, ed. H. Westlund, and K. Kiyoshi, 182-197. Cheltenham: Edward Elgar.

Liu, T., and K.-W. Li. 2001. Impact of liberalization of financial resources in China's economic growth: Provincial evidences. Journal of Asian Economics 12(2): 245-268.

- 2006. Disparity in factor contributions between coastal and inner provinces in post-reform China. China Economic Review 17(4): 449-470.

Martin, R. 2000. Institutional approach in economic geography. In A companion to economic geography, ed. E. Sheppard, and T. Barnes, 77-94. Oxford: Blackwell.

Ministry of Civil Affairs of China. 1991-2011. China civil affairs' statistical yearbook. Beijing: China Statistics Press.

Mohan, G., and J. Mohan. 2002. Placing social capital. Progress in Human Geography 26(2): 191-210.

Omori, T. 2001. Balancing economic growth with well-being: Implications of the Japanese experience. Isuma 2: 87-93.

Pan, F.H., and C. He. 2010. Regional difference in social capital and its impact on regional economic growth in China. Chinese Geographical Science 20(5): 442-449.

Putnam, R. 2000. Bowling alone: The collapse and revival of American community. New York: Simon \& Schuster.

Putnam, R., R. Leonardi, and N. Raffaella. 1993. Making democracy work: Civic traditions in modern Italy. Princeton, NJ: Princeton University Press.

Qian, X.L., and R. Smyth. 2005. Growth accounting for the Chinese provinces 1990-2000: Incorporating human capital accumulation. Discussion Paper 11/05, Department of Economics, Monash University.

Schultz, T. 1961. Investment in human capital. American Economic Review 51(1): 1-17.

Shen, K.R., and Y. Tian. 2002. Human capital and the location choice of the foreign direct investment (in Chinese). Management World 11: 26-31.

Swank, D. 1996. Culture, institutions and economic growth: Theory, recent evidence and the role of communitarian polities. American Journal of Political Science 40(3): 660-679.

Thrift, N., and K. Olds. 1996. Refiguring the economic in economic geography. Progress in Human Geography 20(3): 311-337.

Urel, B., and H. Zebregs. 2009. The dynamics of provincial growth in china: A nonparametric approach. IMF Staff Papers 56(2): 239-262. 


\section{8}

Walder, A.G. 1986. Communist neo-traditionalism. Berkeley, CA: University of California Press.

Wang, S.G., and S. Hu. 1999. The political economy of uneven development: The case of China. New York: M.E. Sharpe.

Wang, Y., and Y. Yao. 2003. Sources of China's economic growth 1952-1999: Incorporating human capital accumulation. China Economic Review 14(1): 32-52.

Westlund, H. 2006. Social capital in the knowledge economy: Theory and empirics. Cheltenham: Edward Elgar.

- 2007. Book review: "Social capital, networks and economic development: An analysis of regional productive systems-By Maria Semitiel Garcia”. Papers in Regional Science 86(4): 657-659.

Westlund, H., and F. Adam. 2010. Social capital and economic performance: A quasi meta-analysis of 65 studies. European Planning Studies 6: 893-919.

Westlund, H., and R. Bolton. 2003. Local social capital and entrepreneurship. Small Business Economics 21: 77-113.

Whiteley, P. 2000. Economic growth and social capital. Political Studies 48(3): 443-466.

Yusuf, S. 1994. China's macroeconomic performance and management during transition. Journal of Economic Perspectives 8(2): 71-92.

Zak, P., and S. Knack. 2001. Trust and growth. Economic Journal 111(470): 295-321.

Zhang, C.G., and L. Zhuang. 2010. The composition of human capital and economic growth: Evidence from China using dynamic panel data analysis. China Economic Review 22(1): 165-171.

Zhang, W.Y., and R. Ke. 2002. Trust in China: A cross-regional analysis (in Chinese). Economic Research Journal 10: 59-70.

\section{Appendix 1}

\begin{tabular}{lll}
\hline Variable & Source & \multicolumn{1}{c}{ Variable description } \\
\hline GGDP & NBS & Per capita GDP growth \\
INV & NBS & Investment ratio \\
Human & NBS & Ratio of university students to total population \\
Social & NBS & Number of associations possessed by per 10,000 persons \\
SOE & NBS & Ratio of industrial output of state-owned enterprises to \\
& & total industrial output \\
Government & NBS & Government expenditure to GDP ratio \\
Trade & NBS & Import and export at current price \\
FDI & NBS & FDI inflow to GDP ratio \\
\hline
\end{tabular}

FDI, foreign direct investment; GDP, gross domestic product; GGDP, growth of per capita GDP; NBS, National Bureau of Statistics; SOE, state ownership. 
PHYSICAL CAPITAL, HUMAN CAPITAL, AND SOCIAL CAPITAL 149

Appendix 2

\begin{tabular}{lccccc}
\hline Variable & Obs. & Mean & SD & Min. & Max. \\
\hline GGDP & 870 & 0.098 & 0.043 & -0.097 & 0.39 \\
LNGDP & 870 & 7.311 & 0.963 & 5.279 & 10.296 \\
INV & 870 & 0.435 & 0.124 & 0.153 & 0.982 \\
Human & 870 & 0.007 & 0.008 & 0.0004 & 0.064 \\
Social & 609 & 1.37 & 0.625 & 0.42 & 4.210 \\
GOV & 866 & 0.144 & 0.063 & 0.048 & 0.548 \\
SOE & 870 & 0.606 & 0.198 & 0.107 & 0.938 \\
Trade & 860 & 0.239 & 0.347 & 0.006 & 2.203 \\
FDI & 870 & 0.024 & 0.033 & 0.000005 & 0.243 \\
\hline
\end{tabular}

FDI, foreign direct investment; GGDP, growth of per capita GDP; SD, standard deviation; SOE, state ownership. 